\title{
Estrutura do componente arbóreo de uma floresta estacional decidual ripária em Jaguari, RS
}

\author{
Structure of the tree component of a riparian seasonal decidual forest in Jaguari, RS, Brazil
}

\author{
Rafael Marian Callegaro ${ }^{\mathrm{I}}$ Solon Jonas Longhi" Ana Claudia Bentancor Araujo ${ }^{\mathrm{III}}$ \\ Maria Raquel Kanieski ${ }^{\mathrm{IV}}$ Paulo Alfonso Floss ${ }^{\mathrm{V}}$ Cibele Rosa Gracioli $^{\mathrm{IV}}$
}

RESUMO

Este estudo analisou a estrutura do componente arbóreo de uma mata ciliar, no município de Jaguari, RS. A amostragem foi realizada em 15 parcelas de $10 \mathrm{~m} \times 10 \mathrm{~m}$ instaladas ao longo da mata ciliar de um afluente do rio Jaguari. Nessas parcelas, foram identificados e medidos os indivíduos com diâmetro à altura do peito (DAP) maior ou igual a $5 \mathrm{~cm}$. Podocarpus lambertii, Sebastiania commersoniana e Lithrea molleoides foram as espécies mais representativas da mata ciliar. A distribuição diamétrica do componente arbóreo e das espécies lenhosas de maior valor de importância (VI) seguiu o padrão comum a florestas inequiânias, com tendência à forma de "J" invertido, e revelou uma estrutura não balanceada, indicando que não há equilíbrio entre as taxas de mortalidade e recrutamento de indivíduos. A estrutura vertical e as espécies de maior VI apresentaram tendência à distribuição normal, com a maioria dos indivíduos posicionada nas classes intermediárias de altura.

Palavras-chave: fitossociologia, estrato arbóreo, estrutura de comunidade, floresta estacional, planalto meridional.

\section{ABSTRACT}

This study analyzed the tree component structure of a riparian seasonal decidual forest, in Jaguari, RS. Data was collected in $1510 \mathrm{mx} 10 \mathrm{~m}$-plots randomly assigned along the riparian forest of a Jaguari river tributary. In these plots trees showing $\mathrm{DBH}$ equal or above $5 \mathrm{~cm}$ were identified and measured. Podocarpus lambertii, Sebastiania commersoniana and Lithrea molleoides were the most representative species of the riparian forest. The tree diameter distribution in general and for the species with the higher importance value index showed the inverted " $J$ " trend, typical of uneven-aged forests, and unbalanced structure resulting from different mortality and recruitment rates. The vertical and height species structure showing the highest importance value tended to normal distribution, with most of the individuals positioned in or close to the average height class.

Key words: phytosociology, tree stratum, community structure, riparian forest, southern plateau.

\section{INTRODUÇÃO}

No Rio Grande do Sul, a Floresta Estacional Decidual abrange 1.176.245ha, o que corresponde a 23,8\% das florestas e constitui a mais extensa formação fitogeográfica do Estado (RIO GRANDE DO SUL, 2002). Geralmente, os remanescentes de Floresta Estacional Decidual, assim como as demais formações florestais do Rio Grande do Sul, apresentam-se fragmentados, formando florestas secundárias em diferentes estágios de sucessão. No Rebordo do Planalto Meridional, as áreas de encosta e as matas ciliares retêm boa parte dos fragmentos de Floresta Estacional, apresentando variação florística e estrutural conforme cada ambiente.

\footnotetext{
IPrograma de Pós-graduação em Engenharia Florestal, Universidade Federal de Santa Maria (UFSM), 97105-900, Santa Maria, RS Brasil. E-mail: mariancallegaro@yahoo.com.br. Autor para correspondência.

IIDepartamento de Ciências Florestais, UFSM, Santa Maria, RS Brasil.

IIIInstituto Federal Farroupilha, Alegrete, RS, Brasil.

IVPrograma de Pós-graduação em Engenharia Florestal, Universidade Federal do Paraná (UFPR), Curitiba, PR, Brasil.

vEmpresa de Pesquisa Agropecuária e Extensão Rural de Santa Catarina, Chapecó, SC, Brasil.

vIUniversidade Federal do Pampa, São Gabriel, RS, Brasil.
} 
A presença de impactos negativos, como desmatamento e extração desordenada de madeira, pode ocasionar o desequilíbrio ecológico em uma floresta, diminuindo a biodiversidade e alterando a estrutura, necessárias à perpetuidade do ecossistema local. Para a manutenção de florestas, como as matas ciliares, é essencial conhecer a sua estrutura, pois revela como estão arranjadas as espécies e fornece informações sobre a dinâmica sucessional.

A caracterização da estrutura de florestas naturais tem sido foco de pesquisa, em que são observadas a estrutura horizontal (densidade, frequência, dominância e valor de importância), a estrutura vertical e a estrutura diamétrica de comunidades arbóreas (ALVES JÚNIOR et al., 2007; LONGHI et al., 2008; ARRUDA et al., 2011). O conhecimento de populações de espécies arbóreas também é significante, podendo identificar espécies melhor adaptadas a uma determinada vegetação, as quais tendem a ser responsáveis pela manutenção dessa formação.

A análise de matas ciliares com área reduzida é necessária, pois essas matas tendem a apresentar uma dinâmica sucessional e uma estrutura diferente das observadas em formações florestais de áreas extensas e em estágios mais avançados de desenvolvimento.

Na região do presente estudo, onde se inclui o município de Jaguari, as formações florestais de tamanho reduzido normalmente não são pesquisadas, devido, em parte, às alterações e à área reduzida dessas florestas. No entanto, fica evidente a importância de formações como as matas ciliares, pois englobam parte da biodiversidade da Floresta Estacional do Rio Grande do Sul, auxiliando na conservação da fauna e da flora regional e, conforme ARAÚJO et al. (2004), fornecem proteção aos rios, servindo de anteparo à erosão, filtragem de sedimentos e produtos químicos de lavouras.

Nesse contexto, o trabalho teve como objetivo diagnosticar as estruturas horizontal, vertical e diamétrica do componente arbóreo de uma floresta ripária (mata ciliar), no município de Jaguari, no Estado do Rio Grande Sul, Brasil.

\section{MATERIAL E MÉTODOS}

O estudo foi realizado em uma mata ciliar de um afluente de $1^{\mathrm{a}}$ ordem (DURLO \& SUTILI, 2005) do rio Jaguari, com altitude média de $148 \mathrm{~m}$, localizada nas

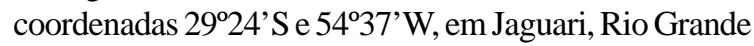
do Sul, Brasil. A mata ciliar, que abrange pequenas faixas ao longo do curso de água perene, com nível normal de água de 3m de largura, está localizada em uma propriedade rural de criação de bovinos. Parte da propriedade era destinada à atividade agrícola, cedendo espaço para pecuária há cerca de 25 anos. O fragmento é formado por uma floresta secundária, em que, atualmente, não há intervenção antrópica direta. No entanto, a mata ciliar não é protegida contra o acesso de animais, que, esporadicamente, têm livre acesso à vegetação ciliar.

O clima da região, segundo a classificação climática de Köppen, é do tipo Cfa (subtropical úmido), com chuvas bem distribuídas em todos os meses do ano, com temperatura do mês mais quente superior a $22^{\circ} \mathrm{C}$ e a do mês mais frio, entre -3 e $18^{\circ} \mathrm{C}$ (MORENO, 1961). A área onde foi realizado o estudo possui relevo levemente ondulado e solo Argissolo Vermelho (STRECK et al., 2008). O tipo fitogeográfico da região pertence à Floresta Estacional Decidual (IBGE, 1962).

Quinze parcelas de $10 \mathrm{mx} 10 \mathrm{~m}$ foram demarcadas aleatoriamente onde a largura da floresta permitiu a alocação das parcelas sem que englobassem a área de pastoreio adjacente, totalizando 0,15ha de superfície amostral. Nas parcelas, foram identificados e medidos os indivíduos com diâmetro à altura do peito (DAP) maior ou igual a 5,0cm. Coletou-se material botânico, das espécies não identificadas a campo, para análise taxonômica no Herbário do Departamento de Ciências Florestais da Universidade Federal de Santa Maria. A determinação das espécies seguiu o sistema de classificação APG III (2009). A confirmação e atualização dos nomes científicos deram-se por meio de consulta ao MBG (2011).

A avaliação da estrutura horizontal foi realizada por meio do cálculo dos parâmetros fitossociologicos densidade (indivíduos ha-1), frequência (\% de parcelas em que a espécie foi amostrada), dominância (área basal da espécie em m²) de cada espécie, os quais foram utilizados para obter o respectivo valor de importância e determinar as espécies mais representativas da estrutura horizontal. Para a análise da estrutura diamétrica e da estrutura vertical, seguiu-se o procedimento de Spiegel, descrito por FELFILI \& REZENDE (2003), utilizando o DAP e a altura fitossociológica, respectivamente. A partir deste procedimento, as árvores foram distribuídas em dez classes de diâmetro, com 5,1cm de intervalo de classe, e em dez classes de altura, com 1,6m de intervalo de classe. Conforme SCHNEIDER \& FINGER (2000), foi realizado o ajuste das frequências em classes diamétricas com a equação de Meyer e calculado o Quociente de Liocourt para o componente arbóreo. 


\section{RESULTADOS E DISCUSSÃO}

O número de indivíduos por hectare encontrado na mata ciliar avaliada (3.060 indivíduos $h^{-1}$ ) foi considerado elevado, quando comparado aos trabalhos realizados por BUDKE et al. (2004) em Floresta Estacional Decidual ribeirinha (2.332 indivíduos ha-1 ${ }^{-1}$ e LONGHI et al. (2008) em Floresta Estacional Semidecidual (2.106 indivíduos ha-1) no Rio Grande do Sul. Conforme esses autores, o grande número de indivíduos encontrados indica que a mata ciliar é jovem e está em estágio secundário de regeneração.

As espécies de maior densidade foram Sebastiania commersoniana, com 806,7 indivíduos ha-1 (Densidade Relativa (DR)=26,4\%), Podocarpus lambertii, com 493,3 indivíduos ha ${ }^{-1}(\mathrm{DR}=16,2 \%)$ e Lithrea molleoides, com 346,7 indivíduos ha-1 ( $\mathrm{DR}=11,3 \%)$. Sebastiania commersoniana também apresentou a maior frequência relativa (12,2\%), devido à ocorrência em todas as parcelas amostradas (frequência absoluta $=100 \%$ ) $($ Tabela 1$)$. Resultado semelhante foi encontrado por BUDKE et al. (2004) em uma floresta ribeirinha do mesmo tipo no município de Santa Maria-RS, onde Sebastiania commersoniana apresentou um considerável número de indivíduos, fato que, segundo BIANCHINI et al. (2003), deve-se à preferência dessa espécie por solos úmidos. Além dessa condição, o amplo estabelecimento (densidade e frequência) de Sebastiania commersoniana na mata ciliar pode estar relacionado ao estágio sucessional (floresta secundária).

Podocarpus lambertii teve a maior dominância absoluta $\left(17,6027 \mathrm{~m}^{2} \mathrm{ha}^{-1}\right)$, perfazendo uma dominância relativa de $41,8 \%$, e o maior valor de importância (66,0\%), seguida de Lithrea molleoides (53,7\%) e Sebastiania commersoniana $(39,4 \%)$, as quais contribuem com 53,0\% do valor total (300\%) do VI. A elevada importância de Podocarpus lambertii também foi encontrada por LONGHI et al. (1992), em um pequeno fragmento florestal no município de São Sepé-RS, indicando que a espécie tem amplo desenvolvimento em florestas naturais de tamanho reduzido. Embora CARVALHO (2004) classifique Podocarpus lambertii como uma espécie secundária tardia ou clímax tolerante à sombra, observações de campo na área de estudo e na região dos Campos Sulinos indicam que a espécie é secundária inicial, dominando a borda de pequenos fragmentos. Isso explica em parte a elevada importância de Podocarpus lambertii na floresta ripária e sugere que a espécie, por dominar uma floresta secundária, pode ser substituída em estágios mais avançados da sucessão florestal.

As árvores mortas apresentaram um alto valor de importância (18,7\%), com consideráveis valores de frequência, dominância e densidade. O estágio de sucessão da floresta é um fator que pode ter determinado a alta importância de árvores mortas na mata ciliar, conforme constatou VACCARO et al. (1999), ao encontrar maior porcentagem de indivíduos mortos em uma floresta secundária do que nas fases inicial (capoeirão) e final (floresta madura) de sucessão. Para LONGHI et al. (1999), as florestas secundárias apresentam maior porcentagem de árvores mortas, devido, dentre outros fatores, ao processo natural de sucessão em que ocorre substituição de espécies pioneiras.

A distribuição dos indivíduos nas classes diamétricas mostrou a tendência à forma de J-invertido, com maior concentração de árvores nas classes inferiores (Figura 1a). Pode-se observar que 91,3\% dos

Tabela 1 - Estrutura horizontal das principais espécies arbóreas de uma floresta ripária. Jaguari, RS. 2009.

\begin{tabular}{|c|c|c|c|c|}
\hline Nome científico & $\mathrm{DR}^{*}(\%)$ & FR (\%) & DoR (\%) & VI (\%) \\
\hline Podocarpus lambertii Klotzsch ex Endl. & 16,1 & 8,1 & 41,8 & 66,0 \\
\hline Sebastiania commersoniana (Baill.) L.B. Sm. \& Downs & 26,4 & 12,2 & 15,2 & 53,7 \\
\hline Lithrea molleoides (Vell.) Engl. & 11,3 & 8,1 & 19,9 & 39,4 \\
\hline Eugenia uniflora L. & 7,6 & 8,1 & 2,7 & 18,4 \\
\hline Eugenia uruguayensis Cambess. & 6,5 & 5,7 & 2,9 & 15,2 \\
\hline Schinus terebinthifolius Raddi & 4,4 & 4,1 & 1,4 & 9,9 \\
\hline Myrcia oblongata DC. & 4,4 & 3,3 & 1,6 & 9,2 \\
\hline Symplocos tetrandra Mart. & 2,0 & 4,1 & 1,1 & 7,2 \\
\hline Zanthoxylum rhoifolium Lam. & 1,5 & 4,1 & 1,1 & 6,7 \\
\hline Eugenia hyemalis Cambess. & 3,5 & 1,6 & 1,0 & 6,1 \\
\hline Mortas & 6,5 & 8,9 & 3,3 & 18,7 \\
\hline Outras (20 espécies) & 9,8 & 31,7 & 8,0 & 49,5 \\
\hline Total & 100,0 & 100,0 & 100,0 & 300,0 \\
\hline
\end{tabular}

*DR= densidade relativa; $\mathrm{FR}=$ frequência relativa; $\mathrm{DoR}=$ dominância relativa; $\mathrm{VI}=$ valor de importância. 

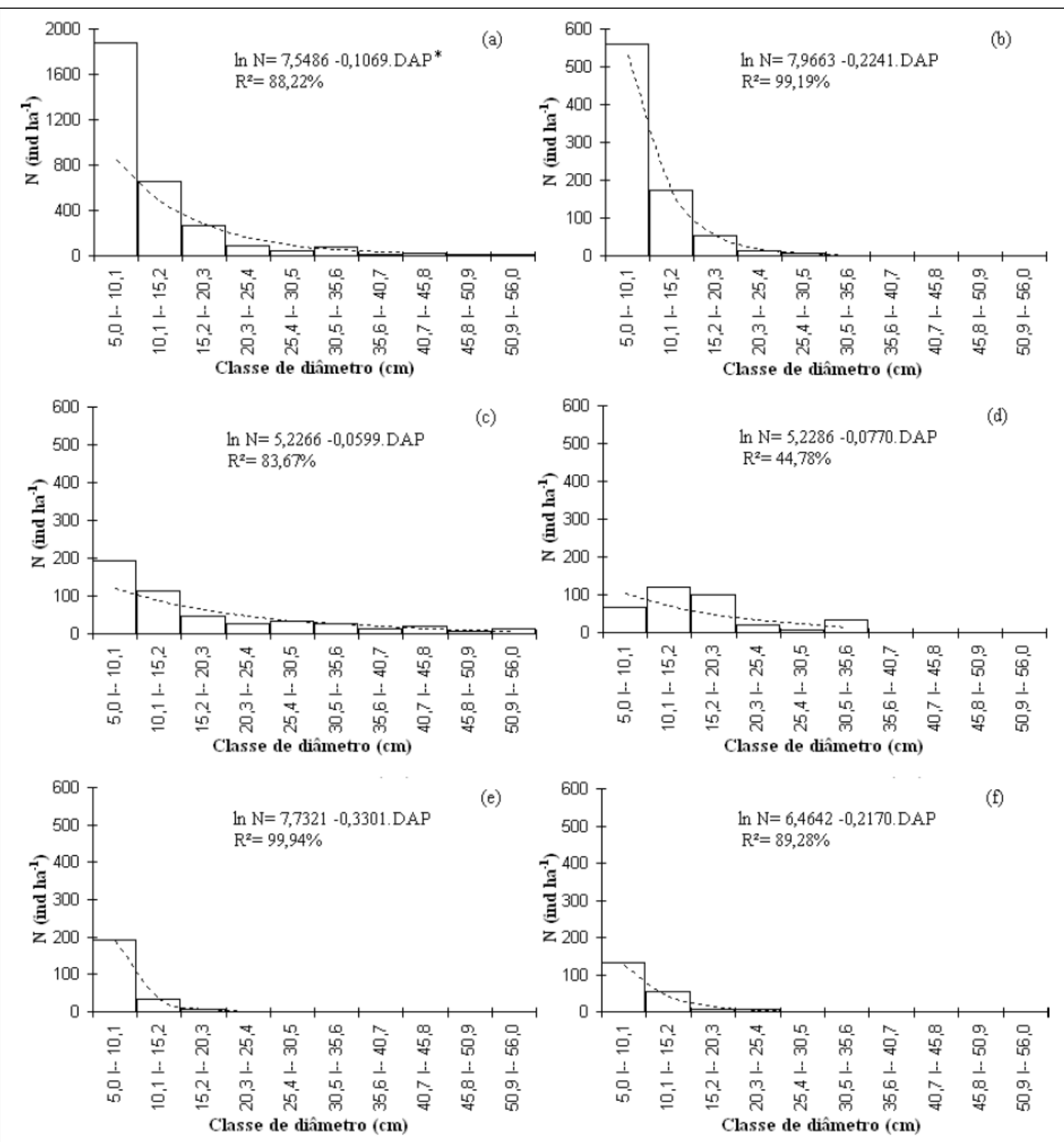

Frequência observada - - - - Frequência ajustada

Figura 1 - Distribuição de frequências observadas e ajustadas em classes diamétricas do componente arbóreo (Figura 1a) das espécies Sebastiania commersoniana (Figura 1b), Podocarpus lambertii (Figura 1c), Lithrea molleoides (Figura 1d) e Eugenia uniflora (Figura 1e), e de árvores mortas (Figura 1f) em uma floresta ripária. Jaguari, RS, Brasil, 2009. * DAP = diâmetro à altura do peito.

indivíduos amostrados restringem-se ao intervalo de DAP entre 5,0 e 20,3cm. A distribuição diamétrica em “J” invertido indica que a floresta tem capacidade de auto-regeneração e de manutenção dos níveis atuais de densidade (NASCIMENTO et al., 2004), e sugere que a mata ciliar tende a manter esse padrão de estrutura diamétrica. No entanto, a curva de frequência ajustada pela equação de Meyer revela que a estrutura diamétrica da mata ciliar não se encontra balanceada, com déficit de indivíduos nas classes diamétricas com pontos médios iguais a 17,8, 22,9cm, 28,0 e 38,2cm. Esta estrutura indica desequilíbrio entre as taxas de 
mortalidade e recrutamento de indivíduos no componente arbóreo, podendo levar a mudanças na atual estrutura da floresta (FELFILI et al., 1998; NASCIMENTO et al., 2004). Conforme MACHADO et al. (2004), fatores inerentes à fragmentação, como forma e tamanho do fragmento florestal, dificultam o recrutamento de indivíduos de algumas espécies, o que, consequentemente, contribui para a ocorrência de uma estrutura não balanceada. Essa estrutura não balanceada do fragmento estudado sugere que ele se encontra em fase intermediária de desenvolvimento sucessional. Possivelmente, no futuro, as espécies pioneiras tendem a ser substituídas, equilibrando a estrutura diamétrica.

O valor estimado para o Quociente de Liocourt, encontrado no presente estudo $(1,69)$, foi semelhante ao encontrado $(1,7238)$ por GLUFKE et al. (1994) para uma Floresta Estacional Decidual, em Santa Maria, RS. Esses valores são considerados comuns às florestas naturais e indicam que há maior densidade de indivíduos em uma classe de diâmetro qualquer $\left(\mathrm{X}_{\mathrm{i}}\right)$ do que na classe de diâmetro seguinte $\left(\mathrm{X}_{\mathrm{i}+1}\right)$.

A análise da estrutura diamétrica das espécies de maior valor de importância revela que Sebastiania commersoniana (Figura 1b), Podocarpus lambertii (Figura 1c) e Eugenia uniflora (Figura 1e) apresentaram tendência à forma de "J invertido". No entanto, Lithrea molleoides (Figura 1d) apresentou um baixo número de indivíduos com diâmetro entre 5,0 cm e 10,1cm, sugerindo que a espécie teve problemas de recrutamento em períodos mais recentes (NASCIMENTO et al., 2004). Por meio das curvas de frequências diamétricas ajustadas para essas espécies, foi constatado o desequilíbrio entre as taxas de mortalidade e recrutamento de indivíduos, evidenciado pela discrepância entre as frequências observadas e ajustadas. Quando isso ocorre, pode-se inferir que o ciclo de vida das espécies não está se completando (PAULA et al., 2004), significando que esta espécie está sendo paulatinamente substituída por outras de fases mais avançadas da sucessão florestal.

A amplitude de diâmetro das árvores mortas oscilou entre 5,0 e 25,3cm, e a maior densidade (133,3 indivíduos ha ${ }^{-1}$ ) ficou restrita à classe de diâmetro menor (5,0 $\leq \mathrm{DAP}<10,1 \mathrm{~cm})$ (Figura 1f). Quando comparados os limites de diâmetro entre as árvores mortas $(5,0 \leq \mathrm{DAP}<25,4 \mathrm{~cm})$ e o componente arbóreo da mata ciliar (5,0 $\leq \mathrm{DAP}<56,0 \mathrm{~cm})$, foi observada a maior mortalidade das árvores de pequeno porte e a ausência de árvores mortas com diâmetros médios e grandes $(25,4 \leq \mathrm{DAP}<56,0 \mathrm{~cm})$. Esses fatos podem ser relacionados à elevada densidade do estrato arbóreo da mata ciliar (3.060ind ha-1), pois algumas espécies sucumbem a fatores decorrentes da competição, sob influência das árvores dominantes.

Foi observada a tendência de distribuição normal dos indivíduos, com 61,2\% das árvores agrupadas em três classes intermediárias de altura, com valores centrais entre 7,1 e 10,3m, indicando a existência de um dossel intermediário denso (Figura 2a). Além disso, observa-se que a mata ciliar possui baixo porte, característica comum à floresta ribeirinha amostrada por BUDKE et al. (2004), em Santa Maria, RS, na qual poucas árvores apresentaram altura superior a $15 \mathrm{~m}$. As espécies de maior Valor de Importância também apresentaram populações com distribuição de altura tendendo à distribuição normal (Figura 2b, 2c, 2d, 2e). Dessas espécies, Sebastiania commersoniana e Podocarpus lambertii têm a estrutura vertical mais semelhante ao componente arbóreo, sendo consideradas as espécies melhor adaptadas ao dossel florestal. Em contraste, Lithrea molleoides apresentou mais árvores com alturas média e alta do que árvores com estatura baixa. Eugenia uniflora teve a menor amplitude de altura, revelando que as árvores da espécie são restritas aos estratos intermediários e inferiores da estrutura vertical da mata ciliar. Cabe observar que houve maior mortalidade de árvores com baixo porte, provavelmente, devido à maior suscetibilidade dessas árvores às condições críticas de competição no sítio florestal (Figura 2f).

\section{CONCLUSÃO}

A estrutura do componente arbóreo da floresta ripária apresenta as espécies Podocarpus lambertii e Sebastiania commersoniana como mais representativas, devido, em parte, ao fragmento encontrar-se em sucessão secundária.

A estrutura diamétrica sugere que esta formação possui boa capacidade de renovação, porém, não se encontra balanceada, revelando, assim, a possibilidade de mudanças na sua estrutura, devido, em parte, às irregularidades da distribuição das principais espécies. A análise da estrutura vertical permite inferir que a mata ciliar tende a concentrar o maior número de árvores no dossel intermediário, o que foi observado para as espécies de maior valor de importância.

Ciência Rural, v.42, n.2, fev, 2012. 


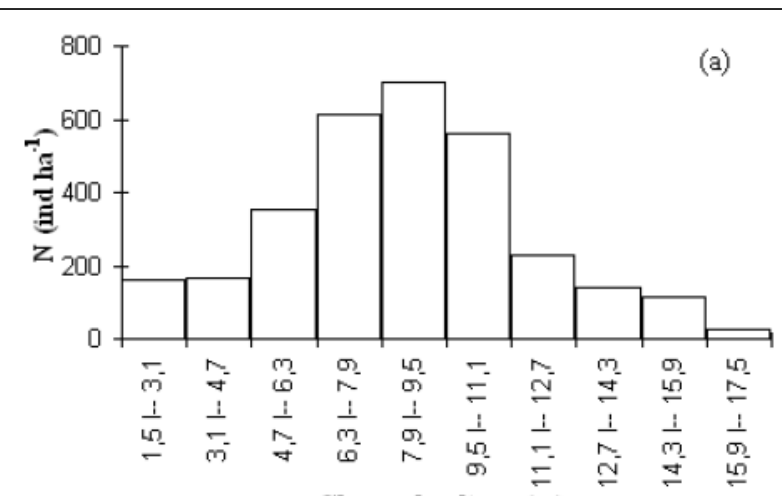

Classe de altura (m)

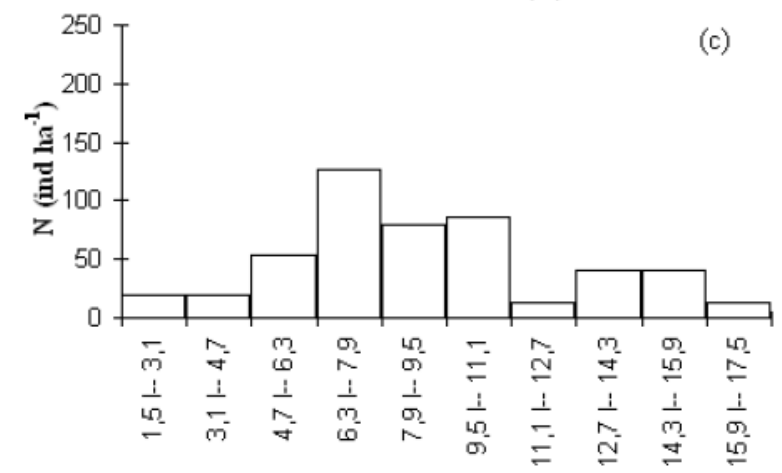

Classe de altura (m)

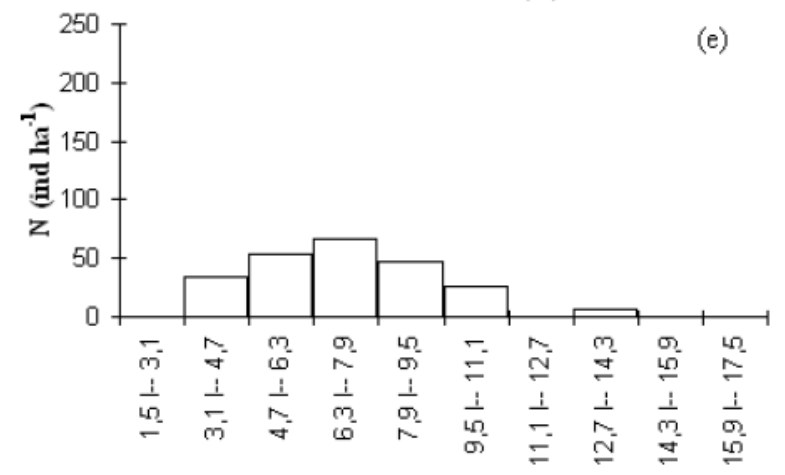

Classe de altura (m)

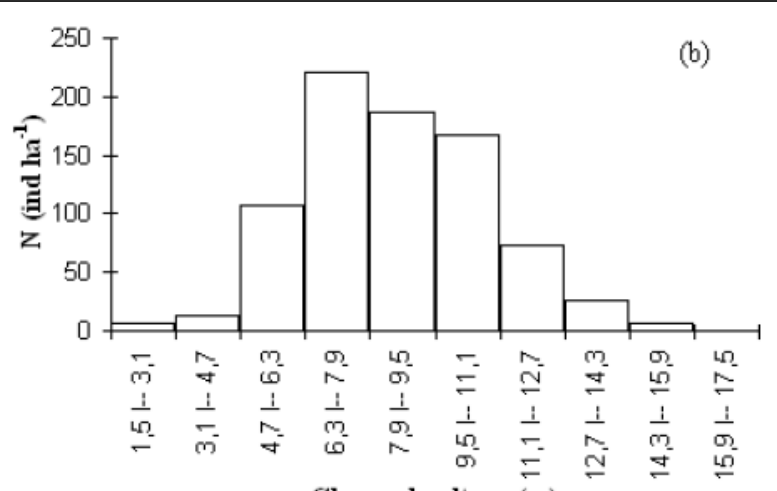

Classe de altura (m)
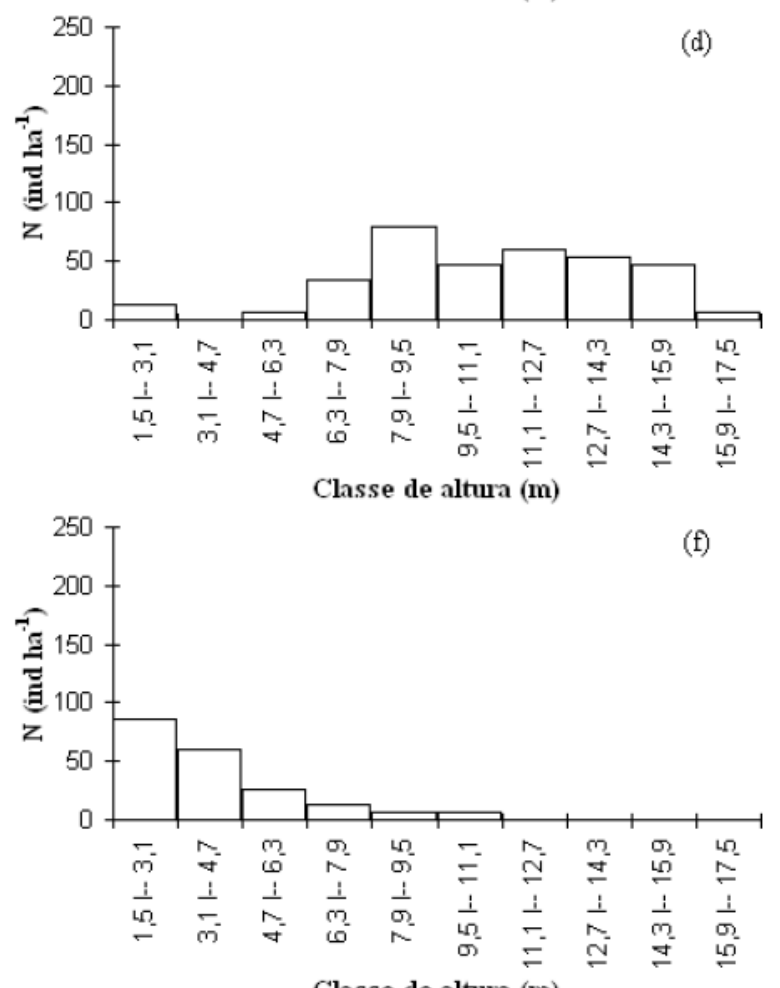

Classe de altura (m)

Figura 2 - Estrutura vertical do componente arbóreo (Figura 2a) das espécies Sebastiania commersoniana (Figura 2b), Podocarpus lambertii (Figura 2c), Lithrea molleoides (Figura 2d) e Eugenia uniflora (Figura 2e), e de árvores mortas (Figura 2f) em uma floresta ripária. Jaguari, RS, Brasil, 2009.

\section{REFERÊNCIAS}

ALVES JÚNIOR, F.T. et al. Estrutura diamétrica e hipsométrica do componente arbóreo de um fragmento de Mata Atlântica, Recife-PE. Cerne, v.13, p.83-95, 2007.

APG III. An update of the Angiosperm Phylogeny Group classification for the orders and families of flowering plants. Botanical Journal of the Linnean Society, v.161, p.105121, 2009. Disponível em: <http://onlinelibrary.wiley.com/ doi/10.1111/j.1095-8339.2009.00996.x/abstract>. Acesso em: 22 ago. 2011. doi: 10.1111/j.1095-8339.2009.00996.x.
ARAÚJO, M.M. et al. Análise de agrupamento da vegetação de um fragmento de floresta estacional decidual aluvial, Cachoeira do Sul, RS, Brasil. Ciência Florestal, v.14, p.133-147, 2004.

ARRUDA, D.M. et al. Structural aspects and floristic similarity among tropical dry forest fragments with different management histories in Northern Minas Gerais, Brazil. Revista Árvore, v.35, p.131-142, 2011. Disponível em: <http://www.scielo.br/ scielo.php?pid=S0100-67622011000100016\&script=sci_arttext>. Acesso em: 22 ago. 2011. doi: 10.1590/S010067622011000100016.

BIANCHINI, E. et al. Diversidade e estrutura de espécies arbóreas em área alagável do município de Londrina, sul do Brasil. Acta 
Botanica Brasílica, v.17, p.405-419, 2003. Disponível em: $<$ http://www.scielo.br/scielo.php?script=sci_arttext\&pid=S0102$33062003000300008 \& \operatorname{lng}=p t \& n r m=i s o \& t \operatorname{lng}=p t>$. Acesso em: 22 ago. 2011. doi: 10.1590/S0102-33062003000300008.

BUDKE, J.C. et al. Florística e fitossociologia do componente arbóreo de uma floresta ribeirinha, arroio Passo das Tropas, Santa Maria, RS, Brasil. Acta Botanica Brasilica, v.18, p.581-589, 2004. Disponível em: <http://www.scielo.br/scielo.php?script=sci_arttext\&pid=S010233062004000300016\&lng=pt\&nrm=iso\&tlng=pt>. Acesso em: 22 ago. 2011. doi: 10.1590/S0102-33062004000300016.

CARVAlHO, P.E.R. de. Pinheiro-Bravo: Podocarpus lambertii. Colombo: Embrapa Florestas. 2004. 9p.

DURLO, M.A.; SUTILI, F.J. Bioengenharia: manejo biotécnico de cursos de água. Porto Alegre: Est Edições, 2005. 192p.

FELFILI, J.M. et al. Levantamento da vegetação arbórea na região de Nova Xavantina, MT. Boletim do Herbário Ezechias Paulo Heringer, v.3. p.63-81, 1998.

FELFILI, J.M.; REZENDE, R.P. Conceitos e métodos em fitossociologia. Brasília: Universidade de Brasília, 2003. 68p.

GLUFKE, C. et al. Produção de uma floresta natural em Santa Maria, RS. Ciência Florestal, v.4, p.61-76, 1994.

IBGE. Manual técnico da vegetação brasileira. Rio de Janeiro: IBGE, 1992. 91p.

LONGHI, S.J. et al. Caracterização fitossociológica do estrato arbóreo em um remanescente de floresta estacional semidecidual, em Montenegro, RS. Ciência Rural, v.38, p.1630-1638, 2008. Disponível em: <http://www.scielo.br/ scielo.php? script =s ci_art text \& pid = S 0103 $84782008000600021 \& \operatorname{lng}=\mathrm{pt} \& \mathrm{nrm}=\mathrm{iso} \& \operatorname{lng}=\mathrm{pt}>$. Acesso em: 22 ago. 2011. doi: 10.1590/S0103-84782008000600021.

LONGHI, S.J. et al. Composição florística e estrutura da comunidade arbórea de um fragmento florestal no município de Santa Maria-Brasil. Ciência Florestal, v.9, p.115-133, 1999

LONGHI, S.J. et al. Composição florística e estrutura fitossociológica de um "capão" de Podocarpus lambertii Klotz., no Rio Grande do Sul. Ciência Florestal, v.2, p.9-26, 1992.
MACHADO, E.L.M. et al. Análise comparativa da estrutura e flora do compartimento arbóreo-arbustivo de um remanescente florestal na fazenda Beira Lago, Lavras, MG. Revista Árvore, v.28, p.499-516, 2004. Disponível em: <http://www.scielo.br/ s cielo.ph p ? s cript = s ci_art text \& pid=S 0100 $67622004000400005 \& \operatorname{lng}=p t \& n r m=i s o \& t \operatorname{lng}=p t>$. Acesso em: 22 ago. 2011. doi: 10.1590/S0100-67622004000400005.

MBG. Tropicos. Saint Louis: Missouri Botanical Garden, 2011. Acesso em: 01 mar. 2011. Online. Disponível em: www.tropicos.org.

MORENO, J.A. Clima do Rio Grande do Sul. Porto Alegre: Secretaria da Agricultura, 1961. 42p.

NASCIMENTO, A.R.T. et al. Florística e estrutura da comunidade arbórea de um remanescente de Floresta Estacional Decidual de encosta, Monte Alegre, GO, Brasil. Acta Botanica Brasilica, v.18, p.659-669, 2004. Disponível em: <http:// www.scielo.br/scielo.php?script=sci_arttext\&pid=S0102$33062004000300023 \& \operatorname{lng}=p t \& n r m=i s o \& \operatorname{lng}=p t>$. Acesso em: 22 ago. 2011. doi: 10.1590/S0102-33062004000300023.

PAULA, A. de. et al. Sucessão ecológica da vegetação arbórea em uma Floresta Semidecidual, Viçosa, MG, Brasil. Acta Botanica Brasilica, v.18, p.407-423, 2004. Disponível em: <http:// www.scielo.br/scielo.php?script $=$ sci_arttext $\&$ pid $=$ S0102 $33062004000300002 \& \operatorname{lng}=p t \& n r m=i s o \& t \operatorname{lng}=p t>$. Acesso em: 22 ago. 2011. doi: 10.1590/S0102-33062004000300002.

RIO GRANDE DO SUL. Governo do Estado. Secretaria Estadual do Meio Ambiente. Inventário Florestal Contínuo do Rio Grande do Sul. 2002. Acesso em: 25 fev. 2011. Online. Disponível em: www.ufsm.br/ifcrs/.

SCHNEIDER, P.R.; FINGER, C.A.G. Manejo sustentado de florestas inequiânias heterogêneas. Santa Maria: UFSM, 2000. 195p.

STRECK, E.V. et al. Solos do Rio Grande do Sul. Porto Alegre: EMATER/RS-ASCAR, 2008. 222p.

VACCARO, S. et al. Aspectos da composição florística e categorias sucessionais do estrato arbóreo de três subseres de uma Floresta Estacional Decidual, no município de Santa Tereza - RS. Ciência Florestal, v.9, p.1-18, 1999. 